\title{
PROJETO E DESENVOLVIMENTO DE UM CARRO ROBÔ CONTROLADO POR SMARTPHONE, UTILIZANDO A PLATAFORMA AMARINO
}

\author{
Otávio de Souza Martins Gomes ${ }^{1}$ \\ Rafael Vinícius Tayette de Nóbrega² \\ Tarlei Almeida ${ }^{3}$ \\ João Paulo Fernandes de Cerqueira César ${ }^{4}$ \\ Rodolfo Labiapari Mansur Guimarães ${ }^{5}$
}

\begin{abstract}
RESUMO
Este artigo mostra a construção de um carro robô controlado por dispositivos móveis utilizando o sistema operacional Android e uma placa de prototipagem open source (Arduino). Utilizou-se de motores para sua movimentação e sensores para interação com o ambiente. O envio de comandos foi realizado utilizando a tecnologia Bluetooth e é capaz de movimentar o carro robô em todas as direções de acordo com os comandos do usuário. Sensores instalados no carro coletam informações do ambiente que são enviadas ao dispositivo Android. A construção bem sucedida deste carro robô mostra que é possível implementar novas funcionalidades para esse produto, bem como apoiar outros projetos relacionados a esse tema.
\end{abstract}

Palavras-chave: Arduino. Android. Bluetooth. Carro robô. Robótica.

\section{PROJECT AND DEVELOPMENT OF A ROBOT CAR CONTROLLED BY SMARTPHONE, USING THE PLATFORM AMARINO}

\begin{abstract}
This work shows the build of a robot car controlled by mobile devices employing Android operating system and an open source prototyping board (Arduino). Motors for its movements and sensors for its environment interaction were employed. The commands are transmitted using Bluetooth technology which can move the robot car in all directions according to the user commands. Sensors installed in the car collect the environment information which is sent to the Android device. The success build of this robot car shows that new features can be possible implemented as well as to support other projects related to this research area.
\end{abstract}

\footnotetext{
${ }^{1}$ Doutorando em Engenharia Elétrica pela Universidade Federal de Itajubá (Unifei), mestrado em Engenharia Elétrica pela Unifei e docente efetivo do Instituto Federal de Minas Gerais - Campus Formiga. E-mail: otavio.gomes@ifmg.edu.br.

${ }^{2}$ Doutorando em Engenharia Elétrica pela Escola de Engenharia de São Carlos Universidade de São Paulo (USP). Mestrado em Engenharia Elétrica pela USP e docente efetivo do Instituto Federal de Minas Gerais Campus Formiga E-mail: rafael.nobrega@ifmg.edu.br.

${ }^{3}$ Graduando em Engenharia Elétrica pelo IFMG - Campus Formiga. E-mail: tarleialmeida@hotmail.com

${ }^{4}$ Graduando em Ciência da Computação pelo IFMG - Campus Formiga. E-mail: joaopaulofcc@gmail.com.

${ }^{5}$ Graduando em Ciência da Computação pelo IFMG - Campus Formiga. E-mail: rodolfolabiapari@gmail.com
} 
Keywords: Arduino. Android. Bluetooth. Robot car. Robotic.

\section{INTRODUÇÃO}

A necessidade da não utilização de cabos em certos dispositivos pôde modelar grande parte da tecnologia, tornando-a mais dinâmica e essencial em um leque bem abrangente de objetivos. Atualmente, com as tecnologias sem fio disponíveis, torna-se mais fácil o desenvolvimento de projetos de campo. Com o auxílio da plataforma de prototipagem open source Arduino, concebida por Massimo Banzi e David Cuartielles em 2005 com objetivo de facilitar o desenvolvimento de sistemas de baixo custo, tais projetos tornaram-se mais acessíveis e fáceis de serem concebidos por qualquer pessoa com o mínimo de conhecimento em eletrônica e programação (ARDUINO, 2014).

Foram estudadas tecnologias e métodos que auxiliassem na construção de um hardware, um firmware e um software para realizar a comunicação entre um dispositivo móvel, com o sistema operacional Android e um carro robô, por meio da plataforma Arduino.

\section{MIT APP INVENTOR}

O MIT App Inventor do Instituto de Tecnologia de Massachusetts é um software de plataforma web que permite aos seus usuários que desenvolvam, testem e exportem seus aplicativos para a plataforma mobile Android (CAMPOS, 2011).

Não é necessário que o usuário digite linhas de código. A programação é feita a partir de blocos de comandos lógicos e funcionais existentes no software, arrastados pelo usuário até a tela de programação. Os blocos formam um quebra-cabeça, que ao final da programação será então compilado. O aplicativo resultante será testado em um simulador disponível pelo software ou no próprio aparelho do usuário e, por fim, exportado para ser instalado em qualquer dispositivo Android.

\section{O TRABALHO PROPOSTO}

\subsection{Hardware e estrutura mecânica}


Foram desenvolvidos alguns protótipos iniciais para testar e verificar quais dispositivos seriam integrados ao robô e escolher quais motores seriam usados. Após essa etapa, foi construída a versão final do carro, que recebeu dos autores o nome de Carduino.

O Carduino é composto por um Arduino Mega 2560, responsável pelo controle de todos os dispositivos, um Adafruit Motor Shield, que permite ao Arduino controlar a velocidade e direção de quatro motores de corrente contínua. Possui um sensor de temperatura e umidade (DHT11) para monitorar o ambiente e um sensor ultrassônico (HC-SR04) que fornece a distância de objetos próximos a ele. Os sensores podem ser monitorados por um display Nokia 5110 fixado no Carduino ou pelo aplicativo. Nesse display o usuário pode ligar e desligar os faróis ou ver os dados dos sensores, por meio de push-buttons. A comunicação é realizada pelo módulo Bluetooth (HC-05), possibilitando ao usuário controlar o Carduino remotamente. Todos esses dispositivos são alimentados por duas pilhas Ultrafire 18560.

A Fig. 1 apresenta a versão final da estrutura mecânica do projeto.

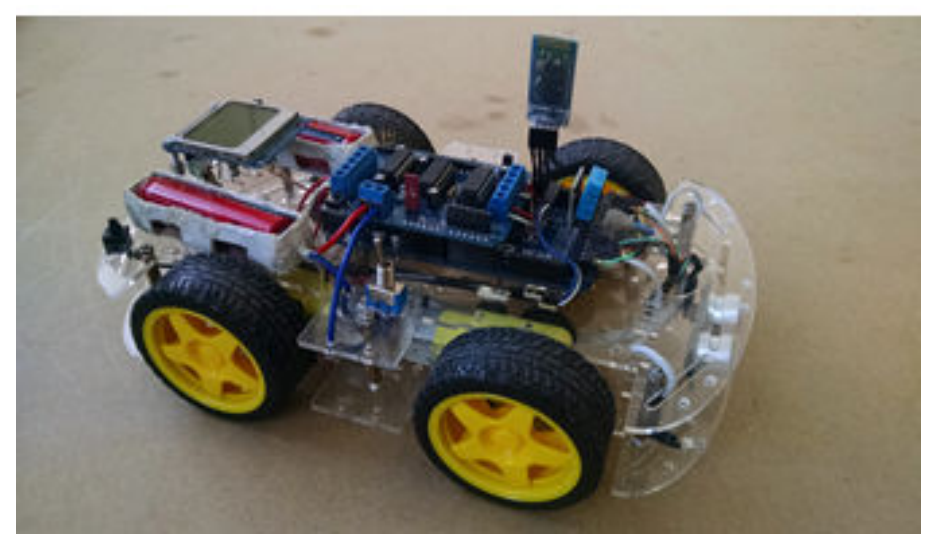

Figura 1 - Estrutural final do Carduino Fonte: Elaborado pelos autores.

\subsection{Firmware}

O firmware do carro foi desenvolvido na linguagem Arduino e é responsável por garantir que os comandos recebidos pelo aplicativo no Android sejam executados de forma correta no carro, além de enviar dados dos sensores para o aplicativo. Todo fluxo de dados realizado entre o carro e o aplicativo ocorre por meio do protocolo de comunicação Bluetooth.

O aplicativo Android envia caracteres para o carro correspondentes a cada tipo de ação executado no aplicativo. Tais ações podem ser referentes à leitura dos sensores, ao movimento dos motores e ao controle dos faróis. Se o Arduino receber o caractere 'F' ele se move para 
frente, ' $T$ ' para trás, ' $D$ ' para a direita, ' $E$ ' para a esquerda; 'L' liga os faróis, ' $M$ ' desliga os faróis e se receber ' $\mathrm{S}$ ' envia os dados dos sensores ao aplicativo.

\subsection{Software}

Após pesquisar sobre inúmeros meios de construir o aplicativo Android, foram encontrados muitos materiais para o desenvolvimento, utilizando o MIT App Inventor (SILVA, 2012). Diante da facilidade encontrada para desenvolver um aplicativo Android nessa ferramenta, foi definido que seria por meio desse que todo o aplicativo seria desenvolvido.

Foram desenvolvidas várias telas para uma melhor interação entre o aplicativo e o usuário, para que essa seja o mais natural e intuitiva possível. Assim, criou-se uma tela inicial na qual o usuário pode realizar todos os comandos disponíveis do carro e acessar as outras janelas como a tela de ajuda, monitoramento dos sensores e página de informações.

As teclas do cabeçalho da tela, da esquerda para direita, representam respectivamente a exibição dos dados dos sensores, controle de velocidade dos motores, controle dos faróis, conectar e desconectar o aplicativo ao carro. Em seguida, tem-se a tela de informações, tela de ajuda e, por fim, o comando de fechar o aplicativo.

O usuário poderá realizar os comandos de movimento por meio das teclas centrais de cor verde que executam ações de direção e de cor preta que executam as ações de parar o carro (clique curto). Na tela de monitoramento, além de os botões da tela inicial serem exibidos, as informações dos sensores instalados no carro também aparecem, como mostra a Fig. 2.

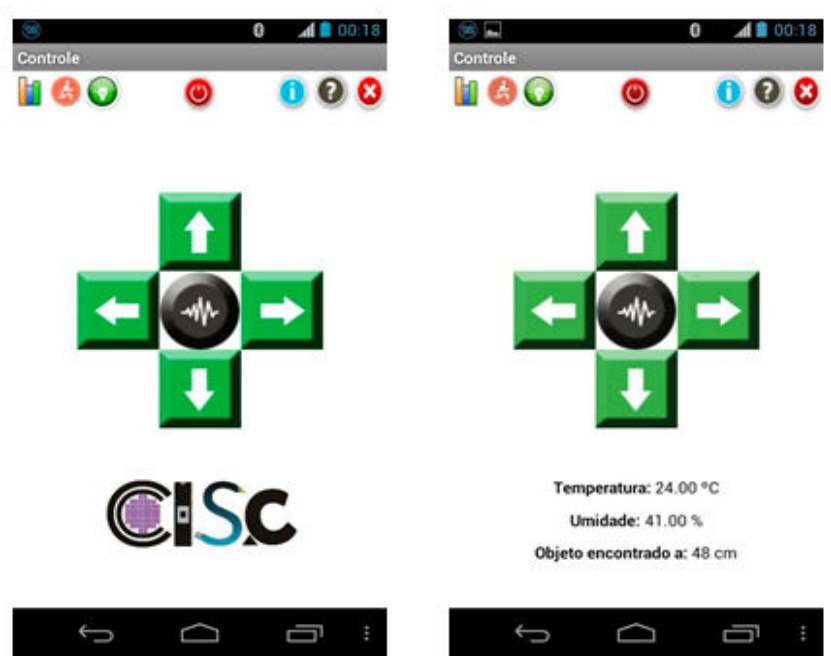

Figura 2 - Telas do aplicativo Android desenvolvido Fonte: Elaborado pelos autores.

ForSci.: r. cient. IFMG campus Formiga, Formiga, v. 2, n. 2, p. 01-06, jul./dez. 2014. 


\section{RESULTADOS E DISCUSSÃO}

Após a conclusão do desenvolvimento do projeto, foram testados tanto o aplicativo quanto o funcionamento e controle do carro. Nos testes, utilizaram-se diversos modelos de dispositivos Android com variadas resoluções de tela e todos obtiveram sucesso.

Todos os requisitos foram cumpridos conforme fora previsto no início do projeto. Nesses primeiros, requisitos contava-se somente o controle do carro por meio do dispositivo Android. Não era esperado que o carro possuísse a complexidade que obteve em seu modelo final, entendendo-se por complexidade o uso de variados sensores, bem como a interação e exibição de informações do carro por meio do display nele acoplado.

Um dos maiores desafios encontrados pelo grupo no desenvolvimento do projeto foi a alimentação do carro. A fonte de alimentação usada inicialmente não conseguia alimentar todos os dispositivos. Tal dificuldade foi amenizada com a aquisição das pilhas Ultrafire.

Outra dificuldade foi a velocidade com que os comandos enviados pelo aplicativo eram interpretados pelo carro devido ao tempo de execução e de leitura desses pelo carro. Tal dificuldade foi parcialmente superada com a otimização da programação de ambos os entes comunicantes (firmware e aplicativo).

Após a conclusão do projeto, foram confeccionados tutoriais didáticos para que outras pessoas possam aprender e reproduzir os métodos e resultados obtidos.

\section{CONCLUSÃO}

O projeto obteve sucesso no seu desenvolvimento, sendo finalizado durante o período estipulado pela instituição de ensino e com o modelo final concluído com as melhorias e incrementos em sua estrutura conforme mostrado na seção 4.

Com a conclusão desse projeto, torna-se mais fácil realizar outros trabalhos de robótica, bem como despertar o interesse de outros estudantes por essa área de pesquisa na instituição.

\section{AGRADECIMENTO}

Os autores agradecem o Instituto Federal de Educação, Ciência e Tecnologia de Minas Gerais - IFMG pelo apoio financeiro para o desenvolvimento do projeto de pesquisa descrito neste artigo e aprovado no Edital: 006/2013. 


\section{REFERÊNCIAS}

ARDUINO. Arduino playground. Disponível em: < http://playground.arduino.cc/Portugues/ HomePage>. Acesso em: 12 dez. 2014.

CAMPOS, A. App Inventor será doado ao MIT, 2011. Disponível em: <https://www.ibm. com/developerworks/mydeveloperworks/blogs/752a690f-8e93-4948-b7a3-c060117e8665/ entry/app_inventor_sera_doado_ao_mit> Acesso em: 12 dez. 2014.

SILVA, E. Tutorial: criando aplicação para android para controlar o arduino através do bluetooth, 2012. Disponível em: <http://labdegaragem.com/forum/topics/tutorial-criandoaplica-o-para-android-para-controlar-o-arduino>. Acesso em: 12 dez. 2014.

Recebido em: 16/11/2014

Aprovado em: 28/11/2014

Publicado em: 26/01/2015 